\section{Cartoon Editorial}

Check for updates

\section{OPEN ACCESS}

Received: May 17, 2019

Accepted: May 21, 2019

Address for Correspondence:

Beom Sun Chung, MD

Department of Anatomy, Ajou University

School of Medicine, 164 World Cup-ro,

Yeongtong-gu, Suwon 16499,

Republic of Korea.

E-mail: bschung@ajou.ac.kr

(c) 2019 The Korean Academy of Medical

Sciences.

This is an Open Access article distributed under the terms of the Creative Commons Attribution Non-Commercial License (https:// creativecommons.org/licenses/by-nc/4.0/) which permits unrestricted non-commercial use, distribution, and reproduction in any

medium, provided the original work is properly cited.

ORCID iDs

Beom Sun Chung (D)

https://orcid.org/0000-0002-3644-9120

Disclosure

The author has no potential conflicts of interest to disclose.

\title{
Classification and Experiment for Psychiatry
}

\section{Beom Sun Chung (D)}

Department of Anatomy, Ajou University School of Medicine, Suwon, Korea

- See the article "Spatiotemporal Analysis of Event-related Current Density Reveals Dissociable Effects of Arousal and Valence on Emotional Picture Processing” in volume 34, number, 20, e146.

\section{(D)}

\section{Classification and experiment for psychiatry}

To classify chemical substances, periodic table was devised.

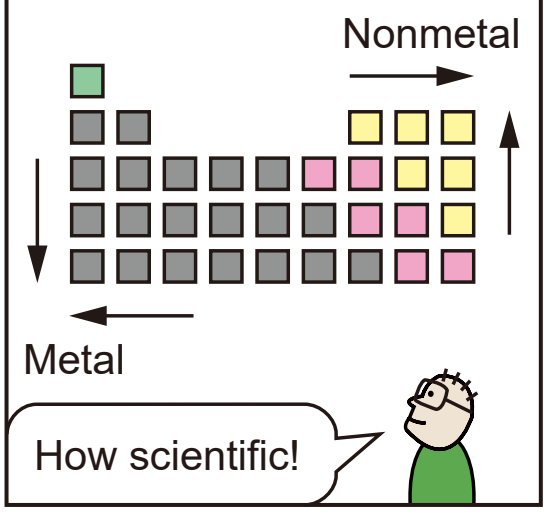

Reactions of chemical substances are discovered by experiment.

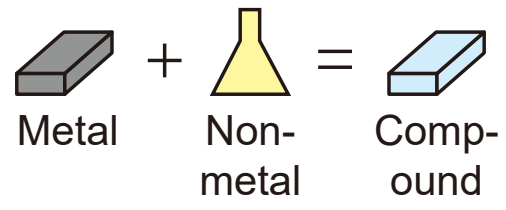

Likewise, cerebral region activated by emotions are discovered by electroencephalography.
Likewise, emotions are classified according to arousal and valence.

High arousal
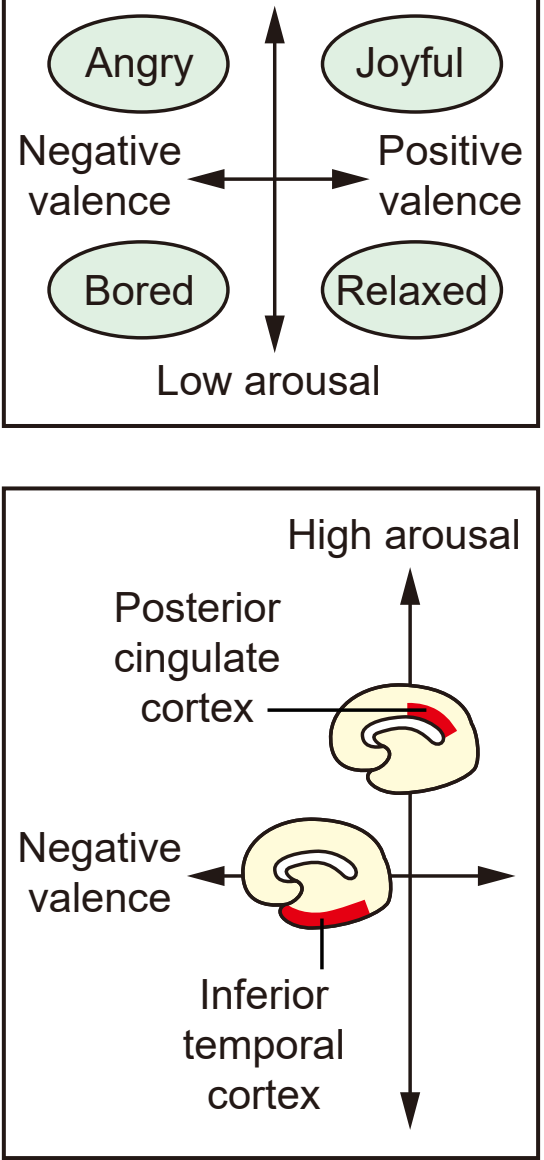